\title{
Palladium-Catalyzed Conjugate Addition of Terminal Alkynes to Enones
}

Lara Villarino, Rebeca García-Fandiño, Fernando López, José L. Mascareñas

\section{Accepted Manuscript}

This document is the Accepted Manuscript version of a Published Work that appeared in final form in ACS Chemical Biology, copyright (C) American Chemical Society after peer review and technical editing by the publisher. To access the final edited and published work see: https://pubs.acs.org/doi/10.1021/ol300988n

\section{How to cite:}

Villarino, L., García-Fandiño, R., López, F., \& Mascareñas, J. (2012). Palladium-Catalyzed Conjugate Addition of Terminal Alkynes to Enones. Org. Lett., 14, 12, 2996-2999. DOI: 10.1021/ol300988n

\section{Copyright information:}

(C) 2012 American Chemical Society 


\title{
Palladium-catalyzed Conjugate Addition of Terminal Alkynes to Enones
}

\author{
Lara Villarino, ${ }^{\dagger}$ Rebeca García-Fandiño, ${ }^{\dagger}$ Fernando López ${ }^{\ddagger, *}$ and \\ José L. Mascareñas ${ }^{\dagger, *}$
}

Centro Singular de Investigación en Química Biolóxica e Materiais Moleculares (CIQUS) and Departamento de Química Orgánica. Unidad Asociada al CSIC, Universidad de Santiago de Compostela, 15782, Santiago de Compostela (Spain) and Instituto de Química Orgánica General CSIC, Juan de la Cierva 3, 28006, Madrid (Spain).

joseluis.mascarenas@usc.es; fernando.lopez@iqog.csic.es

Received Date (will be automatically inserted after manuscript is accepted)

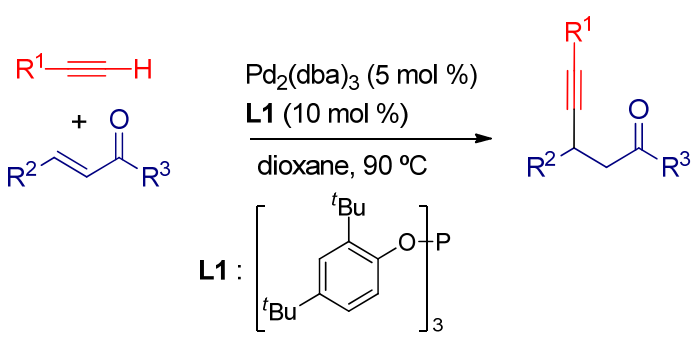

A practical protocol for the hydroalkynylation of enones using $\mathrm{Pd}$ catalysis is reported. The reaction proceeds efficiently with a variety of alkynes as well as with several cyclic and acyclic enones, providing synthetically relevant $\beta$-alkynyl ketones in good to excellent yields.

The transition metal-catalyzed conjugate addition of organometallic reagents to Michael acceptors is an extremely powerful methodology for the construction of C-C bonds. ${ }^{1}$ Particularly interesting is the metalpromoted conjugate addition of terminal alkynes to $\alpha, \beta$ unsaturated carbonyl compounds, because of the synthetic utility of the resulting $\beta$-alkynyl carbonyls. Classical ways to promote these conjugate additions involve the use of stoichiometric amounts of metal alkynylide species, ${ }^{2}$ which unavoidably leads to the generation of significant metallic waste.

In this context, the development of alternative, atomeconomical approaches, based on the catalytic generation of the reactive organometallic species from terminal alkynes, is a highly desirable goal. Recent advances in this field, including the development of some enantioselective variants, have been achieved using $\mathrm{Rh}^{3}{ }^{3}$ $\mathrm{Cu},{ }^{4} \mathrm{Zn},{ }^{5} \mathrm{Ru},{ }^{6}$ or $\mathrm{Co}^{7}$ catalysts. Curiously, and despite the preponderance of $\mathrm{Pd}$ in organometallic catalysis, there are very few precedents on the use of Pd complexes to induce 1,4 -additions of terminal alkynes to $\alpha, \beta$-unsaturated carbonyls. ${ }^{8,9}$ Perhaps this could be due to the tendency of terminal alkynes to react with themselves under $\mathrm{Pd}$ catalysis. ${ }^{10}$ Moreover, the examples reported so far are restricted to the use of $\beta$-unsubstituted acyclic enones and acrylates. ${ }^{8}$ Herein, we report a Pd-based catalytic system which promotes efficient conjugate additions of terminal alkynes to a range of $\alpha, \beta$-unsaturated carbonyls. Importantly, the reaction also works with prochiral $\beta$ substituted acyclic and cyclic enones, therefore allowing the generation of stereocenters in the product. We also include experimental and theoretical data that suggest a

${ }^{1+}$ Universidad de Santiago de Compostela. ${ }^{*}$ Instituto de Química Orgánica General, CSIC 
mechanistic pathway involving a hydropalladation rather than the more commonly proposed alkene carbopalladation.

This work emerged in the context of our research in transition metal-catalyzed alkylidenecyclopropane cycloadditions, ${ }^{11}$ in particular after finding that treatment of terminal alkynes (1) and alkylidenecyclopropanes (2) with specific Pd catalysts generates hydroalkynylated products of type 3 (Scheme 1), ${ }^{12}$ instead of the initially expected $(3+2)$ cycloadducts. ${ }^{13}$ The formation of $\mathbf{3}$ was explained through an initial $\mathrm{C}-\mathrm{H}$ activation process that yields a (hydro)(alkynyl)palladium(II) species A, which subsequently hydropalladates the alkylidenecyclopropane leading to B. A $\beta$-carboelimination followed by reductive elimination would complete the catalytic cycle.

Scheme 1. Previous Pd-catalyzed hydroalkynylations of $2{ }^{12}$

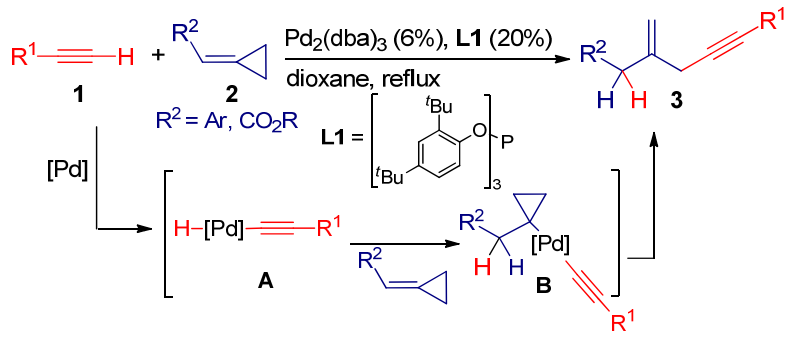

Stimulated by these results, we decided to explore the performance of this Pd catalyst $\left(\mathrm{Pd}_{2}(\mathrm{dba})_{3} / \mathbf{L 1}\right),{ }^{12}$ in the hydroalkynylation of alkenes lacking the cyclopropane moiety. Thus, in a preliminary screening, we tested the hydroalkynylation of styrene and cyclopenten-2-one (4a) using triisopropylsilylacetylene (1a) as alkyne partner. Although styrene did not provide any coupling product, ${ }^{14}$ cyclopenten-2-one participated in the reaction, leading to the desired $\beta$-alkynyl cyclopentanone 5aa in a low 20\% yield (Table 1, entry 1). Enyne products 6a and 6a', arising from the dimerization of the alkyne 1a, were detected as major side products. ${ }^{10}$ Further optimization of the reaction conditions determined that the use of a Pd:L1 ratio of $1: 1$, as well as a slightly lower temperature (90 ${ }^{\circ} \mathrm{C}$ ), favors the conjugate addition over the alkyne dimerization, and thus 5 aa could be obtained in a good $68 \%$ yield (entry 2). ${ }^{15}$ As can be seen in entries 3 and 4, other Pd:L1 ratios turned out to be less efficient, providing 5aa in lower yields. On the other hand, the use of an excess of alkyne (2.5 equiv) was found to be important but not essential for the reaction, as the product could still be obtained in $47 \%$ yield using a $1: 1$ ratio of 1a and 4a (entry 5). Other phosphites such as $\mathrm{P}(\mathrm{OPh})_{3}$ or $\mathrm{P}\left(\mathrm{O}^{i} \mathrm{Pr}\right)_{3}$, as well as alternative $\mathrm{Pd}$ sources, (i.e. $\left.\mathrm{Pd}\left(\mathrm{PPh}_{3}\right)_{4}\right)$, were ineffective, leading to the recovery of $\mathbf{4 a}$ and the formation of mixtures of enynes $\mathbf{6 a} / \mathbf{6} \mathbf{a}$ ' (entries 6-8). We also tested conditions previously used for the Pd-catalyzed alkynylation of $\alpha, \beta$-unsaturated systems: $\quad \operatorname{Pd}(\mathrm{OAc})_{2} / \mathrm{PMe}_{3}{ }^{8},{ }^{8}$ and $\operatorname{Pd}(\mathrm{OAc})_{2} /$ tris(2.6dimethoxyphenyl)phosphine. ${ }^{9}$ However none of the reactions produced the alkyne 5aa, but a mixture of side products majoritarily consisting of alkyne dimers. ${ }^{16}$

Table 1. Preliminary screening on the Pd-catalyzed conjugate addition of triisopropylsilylacetylene to cyclopenten-2-one. ${ }^{a}$

\begin{tabular}{|c|c|c|c|c|c|c|}
\hline \multicolumn{2}{|c|}{${ }^{i} \mathrm{Pr}_{3} \mathrm{Si} \overline{\overline{1 a}}$} & \multicolumn{3}{|c|}{$\begin{array}{l}{[\mathrm{Pd}](\mathrm{x} \mathrm{mol} \%)} \\
\mathbf{L}(\mathrm{y} \mathrm{mol} \mathrm{\% )} \\
\text { solvent, temp }\end{array}$} & ${ }_{5}$ & $\mathrm{Si}^{i} \mathrm{Pr}_{3}$ \\
\hline entry & solvent & $\begin{array}{c}\text { equiv } \\
\text { (1a) }\end{array}$ & $\begin{array}{c}\mathbf{L} \\
(\mathrm{mol} \%)\end{array}$ & $\begin{array}{c}{[\mathrm{Pd}]} \\
(\mathrm{mol} \%)\end{array}$ & $\begin{array}{l}\text { temp } \\
\left({ }^{\circ} \mathrm{C}\right)\end{array}$ & $\begin{array}{c}\text { yield (\%) } \\
\text { 5aa }^{b}\end{array}$ \\
\hline 1 & dioxane & 2.5 & L1 (20) & $\mathrm{Pd}_{2}(\mathrm{dba})_{3}(6)$ & 105 & 20 \\
\hline 2 & dioxane & 2.5 & L1 (10) & $\mathrm{Pd}_{2}(\mathrm{dba})_{3}(5)$ & 90 & 68 \\
\hline 3 & dioxane & 2.5 & L1 (12.5) & $\mathrm{Pd}_{2}(\mathrm{dba})_{3}(5)$ & 90 & 40 \\
\hline 4 & dioxane & 2.5 & L1 (5) & $\mathrm{Pd}_{2}(\mathrm{dba})_{3}(5)$ & 90 & 36 \\
\hline 5 & dioxane & 1 & L1 (10) & $\mathrm{Pd}_{2}(\mathrm{dba})_{3}(5)$ & 90 & 47 \\
\hline 6 & dioxane & 2.5 & $\mathrm{P}(\mathrm{OPh})_{3}(10)$ & $\mathrm{Pd}_{2}(\mathrm{dba})_{3}(5)$ & 90 & $0^{c}$ \\
\hline 7 & dioxane & 2.5 & $\mathrm{P}\left(\mathrm{O}^{i} \mathrm{Pr}\right)_{3}(10)$ & $\mathrm{Pd}_{2}(\mathrm{dba})_{3}(5)$ & 90 & $0^{c}$ \\
\hline 8 & dioxane & 2.5 & $\mathbf{L} 1(0-10)$ & $\mathrm{Pd}\left(\mathrm{PPh}_{3}\right)_{4}(5)$ & 90 & $0^{c}$ \\
\hline \multicolumn{7}{|c|}{$\begin{array}{l}{ }^{a} \text { Conditions: } 4 \mathbf{4 a}\left(1 \text { equiv) and } \mathbf{1 a} \text { at a concentration of } 0.1 \mathrm{M} .{ }^{b}\right. \\
\text { Isolated yields. }{ }^{b} \text { Analysis of the crude reaction mixtures indicated the } \\
\text { presence of starting materials and enynes } \mathbf{6 a} \text { and } \mathbf{6 a} \text { (NMR, GC-MS). }\end{array}$} \\
\hline & & & & 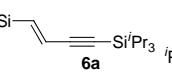 & ${ }_{3} \mathrm{Si}^{Y}$ & $\overline{\text { 6a' }^{\prime}}$ Si'Pr $_{3}$ \\
\hline
\end{tabular}

With optimal conditions at hand, we next screened the addition of triisopropylsilylacetylene (1a) to different Michael acceptors (Table 2). Other cyclic enones such as cyclohexen-2-one (4b) or cyclohepten-2-one (4c) cleanly provided the expected adducts in $70 \%$ and $94 \%$ yield, respectively (Table 2, entries 2, 3). Except for two Rhpromoted cases, ${ }^{3 \mathrm{~d}}$ results from entries 1-3 represent the only examples reported so far involving a direct catalytic conjugate addition of terminal alkynes to cyclic unsaturated systems. Simple acyclic enones such as methyl vinyl ketone (4d) also participated in the process, providing the addition product 5 ad in an excellent $92 \%$ yield (entry 4). More significantly, $\beta$-substituted acyclic enones (4e-4h) reacted with 1a to give the corresponding addition products 5ae-5ah in good to excellent yields (60-92\% yield, entries 5-8). However, further substitution in the $\beta$-position of the enone, such as in $\mathbf{4} \mathbf{i}$, precludes the coupling reaction (entry 9). ${ }^{17}$ Ethyl vinyl ketone $(\mathbf{4 j})$ is also an excellent addition partner for 1a, providing the ketone 5aj in 94\% yield (entry 10). Interestingly, the conjugate addition of $\mathbf{1 a}$ is not limited to $\alpha, \beta$-unsaturated ketones; thus, more challenging enals and enoates like $\mathbf{4 k}$ or $4 \mathbf{l}$ can also participate in the process, ${ }^{18}$ leading to synthetically appealing $\beta$-alkynyl aldehydes and esters, albeit with modest yields (entries 11, 12).

The scope of the reaction with respect to the alkyne component was studied using (E)-pent-3-en-2-one (4e) as alkene partner (Table 3). Although the treatment of phenylacetylene (1b) with this enone under the standard conditions produced only undesired alkyne dimers (entry 1 ), slow-addition of the alkyne to the reaction mixture, allowed to obtain the product 5 be in $50 \%$ yield (entry 2 ). 
Using this modified protocol, the addition of other arylsubstituted alkynes, incorporating methyl groups at the ortho, meta and para positions, as well as electrondonating or withdrawing groups, proceeded satisfactorily, and the corresponding addition products could be isolated in yields ranging from $45 \%$ to $98 \%$ (entries 3-7). Remarkably, while the silyl protected prop-2-yn-1-ol derivative $\mathbf{l h}$ gave a poor yield of the desired product (entry 8), the bulkier analog $\mathbf{1} \mathbf{i}$ gave the desired adduct in excellent yield (89\%, entry 9), probably because the steric bulk minimizes the homodimerization process.

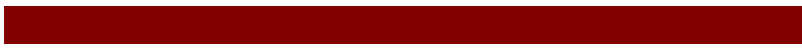

Table 2. Pd-catalyzed conjugate addition of triisopropylsilylacetylene to $\alpha, \beta$-unsaturated carbonyls. ${ }^{a}$

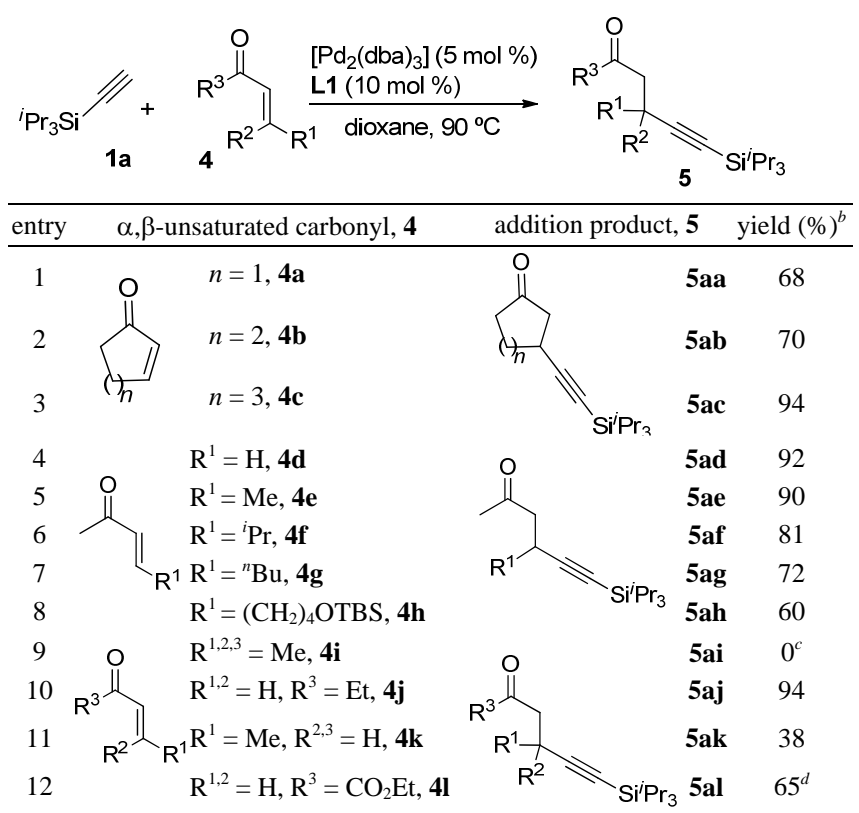

${ }^{a}$ Conditions: 1a (2.5 equiv), 4 (1 equiv), $\mathrm{Pd}_{2}(\mathrm{dba})_{3}(5 \%)$ and $\mathbf{L 1}(10 \%)$ in dioxane $(0.1 \mathrm{M})$ at $90{ }^{\circ} \mathrm{C}$ for $16-24 \mathrm{~h}$, unless otherwise noted. ${ }^{b}$ Isolated yields. ${ }^{c}$ Analysis of the crude reaction mixtures indicated the presence of starting materials and enynes 6a and 6a' (NMR, GC-MS). ${ }^{d}$ Yield corresponds to a 3:1 mixture of 5al and 5al'.

$\mathrm{EtO}_{2} \mathrm{C}-$

5al' $=\mathrm{siPr}_{3}$

At this point, we performed a preliminary test on the viability of rendering the methodology asymmetric, by using chiral phosphorous ligands. Among several chiral phosphines, phosphites or phosphoramidites tested, only phosphite $\mathbf{L} 2^{19}$ was able to promote the conjugate addition reaction of $\mathbf{1 a}$ to $\mathbf{4 e}$. Thus, the catalyst generated from $\mathrm{Pd}_{2}(\mathrm{dba})_{3}(5 \%)$ and $\mathbf{L} 2$ (20\%) afforded 5 ae in an excellent $96 \%$ yield, whereas ketone $5 \mathbf{b e}$, resulting from the addition of $\mathbf{1 b}$ to $\mathbf{4 e}$, could be isolated in $50 \%$ yield (entries 10, 11). ${ }^{20}$ The enantiomeric excesses of the products in both cases are promising, (c.a. $40 \%$ ee) thus, warranting further investigations in this area.

When deuterated phenylacetylene $(\mathbf{1 b}-d)$ was treated with $4 \mathbf{e}$ under the reaction conditions, the corresponding monodeuterated product 5 be- $d$ was obtained (deuterium content: $40 \%){ }^{21,22}$ This result is consistent with a reaction mechanism involving insertion of $\operatorname{Pd}(0)$ into the alkyne sp-C-H bond, followed by either hydropalladation or carbopalladation of the enone, and final reductive elimination.

Table 3. Pd-catalyzed 1,4-addition of terminal alkynes to $\mathbf{4 e} .^{a}$

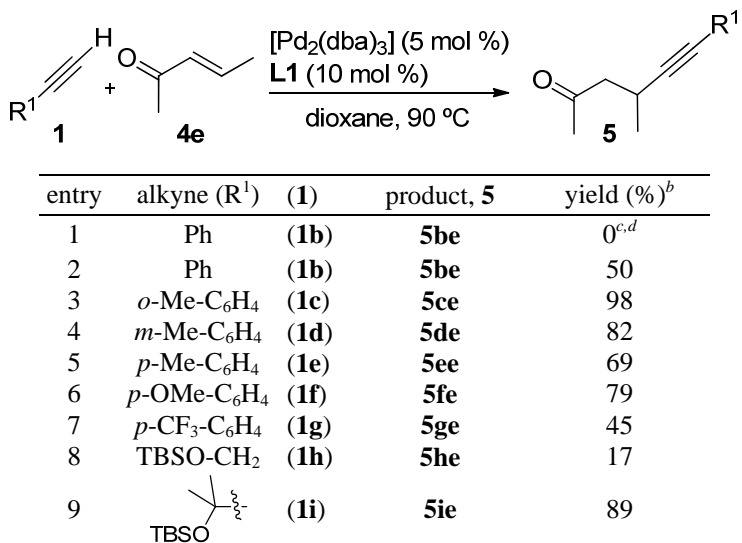

\begin{tabular}{|c|c|c|c|c|}
\hline $10^{\mathrm{c}, e}$ & TIPS & (1a) & 5 ae & $96,39 \%$ eе \\
\hline $11^{e}$ & $\mathrm{Ph}$ & (1b) & 5 be & $50,38 \%$ eе \\
\hline
\end{tabular}

a Conditions: 1a (2.5 equiv) added over $10 \mathrm{~h}$ to a solution of 4 (1 equiv), $\mathrm{Pd}_{2}(\mathrm{dba})_{3}(5 \%)$ and $\mathbf{L 1}(10 \%)$ in dioxane $(0.1 \mathrm{M})$ at $90^{\circ} \mathrm{C}$, unless otherwise noted. Reaction times: $16-24$ h. ${ }^{b}$ Isolated yields. ${ }^{c}$ Alkyne 1b was added in one portion. ${ }^{d}$ Analysis of the crude reaction mixtures indicated the presence of starting materials and enynes $\mathbf{6 b}$ and $\mathbf{6 b} \mathbf{b}^{\mathrm{e}}{ }^{e}$ Carried out with $\mathbf{L} 2(20 \%)$ and $\mathrm{Pd}_{2}(\mathrm{dba})_{3}(5 \%)$.

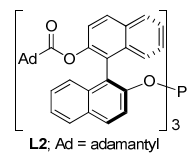

To distinguish between the hydro- or the carbometallation alternative, as well as to obtain a more reliable mechanistic picture of the process, we performed preliminary DFT calculations using enone 4e, prop-1-yne (1j) and $\mathrm{Pd}\left(\mathrm{PH}_{3}\right)$ as model reactant and catalyst (Scheme 2). ${ }^{23}$ The computed data indicate that the reaction starts with the coordination of the Pd catalyst to the $\mathrm{C}-\mathrm{C}$ triple bond, prior to an oxidative addition to the $s p-\mathrm{C}-\mathrm{H}$ bond. This process, which proceeds through transition state TS1, involves an energy barrier of $26.3 \mathrm{kcal} / \mathrm{mol}(\Delta \mathrm{G}$ value) and yields a (hydro)(alkynyl)palladium(II) intermediate int-1. Coordination of the enone followed by carbopalladation generates int-3', through TS2' (energy barrier of $9.6 \mathrm{kcal} / \mathrm{mol}$ ). Alternatively, hydropalladation through TS2 would generate intermediate int-3, which gains stability by coordination of the carbonyl oxygen to the Pd center to give int-4. The hydropalladation process presents an energy cost of 4.0 $\mathrm{kcal} / \mathrm{mol}$ and, therefore, seems to be kinetically favored over the carbometallation. Finally, reductive elimination from int-4 or int-3' leads to the final adduct 5 je. ${ }^{24}$ Although the reductive elimination from the carbopalladation intermediate int-3' is favored compared to that from int-4, overall, the higher energy cost associated to the carbopalladation pathway (via TS2') makes the hydropalladation route most viable. ${ }^{25}$ This mechanistic scenario is therefore different to that 
proposed for other metal-catalyzed alkynylations of $\alpha, \beta$ unsaturated carbonyls, ${ }^{3-8}$ which have been suggested to proceed via carbometallation pathways. ${ }^{26}$ The structures of the key stationary points of the current pathway can be seen in Figure S1 and S2 of the Supporting Information.

Scheme 2. DFT profile of the Pd-catalyzed conjugate addition of $\mathbf{1 j}$ to $\mathbf{4 e}$

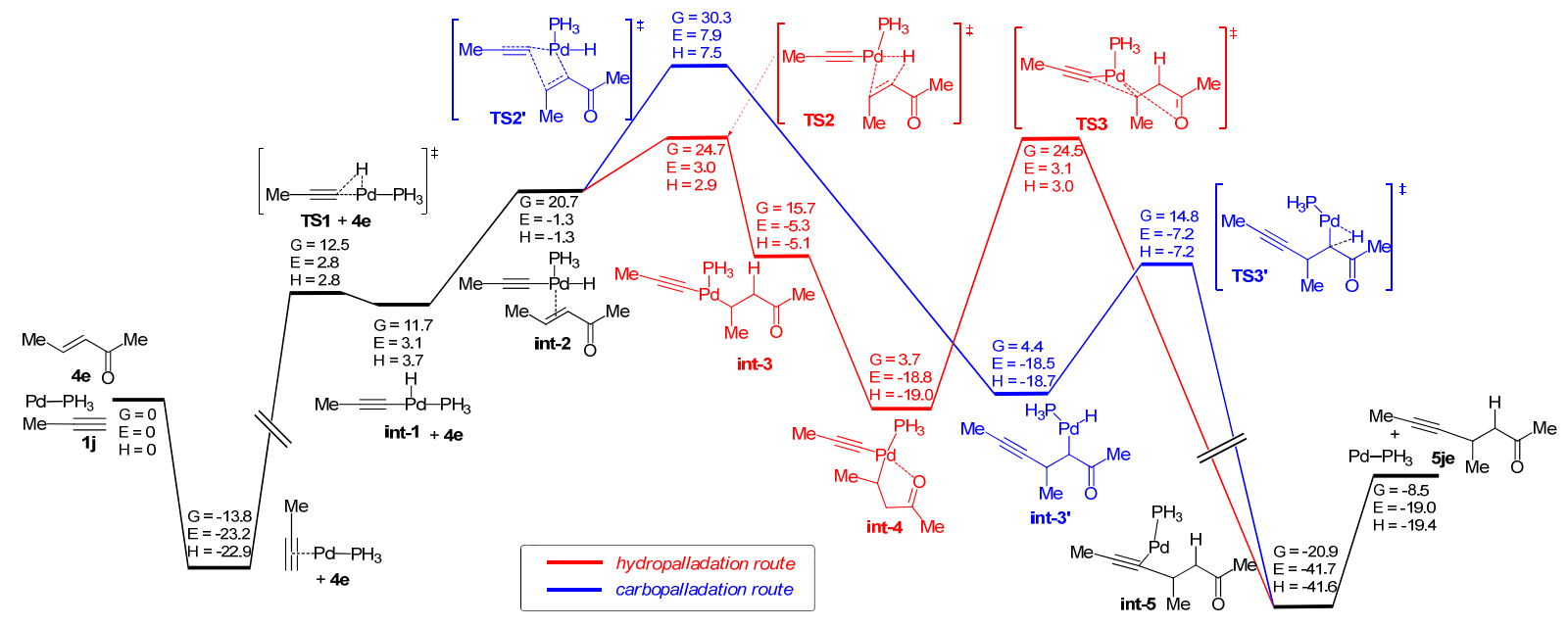

In summary, we have developed a simple and practical Pd-catalyzed methodology for the conjugate addition of terminal alkynes to Michael acceptors, which is particularly efficient in the case of enones. Worth mentioning are the additions to prochiral $\beta$-substituted enones, which had no precedents using Pd-catalysts, as well as the additions to cyclic enones for which only two isolated examples using a Rh catalyst had been reported. $^{3 \mathrm{~d}}$ The development of a highly asymmetric variant, based on our preliminary findings, is under investigation.

Acknowledgment This work was supported by the Spanish MINECO [SAF2007-61015, SAF2010-20822C02, Consolider Ingenio 2010 CSD2007-00006], the ERDF and the Xunta de Galicia INCITE09209084PR, GRC2010/12. LV and RGF thanks the Spanish MEC and MINECO for FPU fellowship and a Juan de la Cierva contract, respectively. Johnson-Matthey is acknowledged for a gift of metals.

Supporting Information Available Experimental procedures, spectroscopy data, DFT calculations, energies and Cartesian coordinates. This material is available free of charge via the Internet at http://pubs.acs.org

(1) (a) Perlmutter, P. Conjugate Addition Reactions in Organic Synthesis; Tetrahedron Organic Chemistry Series 9; Pergamon Press: Oxford, U.K., 1992.

(2) For instance, see: (a) Schwartz, J.; Carr, D. B.; Hansen, R. T.; Dayrit, F. M. J. Org. Chem. 1980, 45, 3053. (b) Kim, S.; Lee, J. M. Tetrahedron Lett. 1990, 31, 7627. (c) Sinclair, J. A.; Molander, G. A.; Brown, H. C. J. Am. Chem. Soc. 1977, 99, 954. (d) Wu T. R.; Chong, J. M. J. Am. Chem. Soc., 2005, 127, 3244. (e) Larionov, O. V.; Corey, E. J. Org. Lett., 2010, 12, 300. (f) Woo, J. C. S.; Cui, S.; Walker, S. D.; Faul, M. M. Tetrahedron 2010, 66, 4730. (g) Cui, S.; Walker, S. D.; Woo, J. C. S.; Borths, C. J.; Mukherjee, H.; Chen, M. J.; Faul, M. M. J. Am. Chem. Soc. 2009, 132, 436. For a review, see: (h) Fujimori, S.; Knöpfel,
T. F.; Zarotti, P.; Ichikawa, T.; Boyall, D.; Carreira, E. M. Bull. Chem. Soc. Jpn. 2007, 80, 1635

(3) (a) Chisholm, J. D.; Lerum, R. V. Tetrahedron Lett. 2004 45, 6591. (b) Nishimura, T. J. Synth. Org. Chem. Jpn. 2008, 66, 1160. (c) Nishimura, T.; Sawano, T.; Hayashi, T. Angew. Chem. Int. Ed. 2009 48, 8057. (d) Nishimura, T.; Guo, X. X.; Uchiyama, N.; Katoh, T.; Hayashi, T. J. Am. Chem. Soc. 2008, 130, 1576. (e) Fillion, E.; Zorzitto, A. K. J. Am. Chem. Soc. 2009, 131, 14608.

(4) (a) Knopfel, T. F.; Zarotti, P.; Ichikawa, T.; Carreira, E. M. J. Am Chem. Soc. 2005, 127, 9682. (b) Knöpfel, T. F.; Carreira, E. M. J. Am. Chem. Soc. 2003, 125, 6054. (c) Yazaki, R.; Kumagai, N.; Shibasaki, M. J. Am. Chem. Soc. 2010, 132, 10275. (d) Fujimori, S.; Carreira, E. M Angew. Chem. Int. Ed. 2007, 46, 4964.

(5) (a) Knöpfel, T. F.; Boyall, D.; Carreira, E. M. Org. Lett. 2004, 6 2281. (b) Kidwai, M.; Jain, A.; Bhardwaj, S. Catal. Lett. 2011, 141, 183.

(6) (a) Nishimura, T.; Washitake, Y.; Uemura, S. Adv. Synth. Catal. 2007, 349, 2563. (b) Uemura, S.; Nishimura, T.; Washitake, Y. Nishiguchi, Y.; Maeda, Y. Chem. Commun. 2004, 1312. (c) Chang, S. Na, Y.; Choi, E.; Kim, S. Org. Lett. 2001, 3, 2089. (d) Picquet, M.; Bruneau, C.; Dixneuf, P. H. Tetrahedron 1999, 55, 3937.

(7) Nishimura, T.; Sawano, T.; Ou, K.; Hayashi, T. Chem. Commun. 2011, 47, 10142 .

(8) (a) Jiang, H. F.; Zhou, L.; Chen, L.; Skouta, R.; Li, C. J. Org. Biol. Chem. 2008, 6, 2969. (b) Li, C. J.; Chen, L. Chem. Commun. 2004, 2362.

(9) For Pd-catalyzed hydroalkynylations of ynoates and allenoates, see: (a) Trost, B. M.; Sorum, M. T.; Chan, C.; Harms, A. E.; Rühter, G. J. Am. Chem. Soc. 1997, 119, 698. (b) Trost, B. M.; Kottirsch, G. J. Am Chem. Soc. 1990, 112, 2816. (c) Rubin, M.; Markov, J.; Chuprakov, S.; Wink, D. J.; Gevorgyan, V. J. Org. Chem. 2003, 68, 6251.

(10) The homo-dimerization of terminal alkynes is a well-known process. For selected examples, see: (a) Trost, B. M.; Chan, C., Ruhter, G. J. Am. Chem. Soc. 1987, 109, 3486. (b) Rubina, M.; Gevorgyan, V. J. Am. Chem. Soc. 2001, 123, 11107. (c) Nishiura, M.; Hou, Z.; Wakatsuki, Y.; Yamaki, T.; Miyamoto, T. J. Am. Chem. Soc. 2003, 125, 1184.

(11) Mascareñas, J. L.; Gulías, M.; López, F. Pure. Appl. Chem. 2011, 83, 495.

(12) Villarino, L.; López, F.; Castedo, L.; Mascareñas, J. L. Chem. Eur. J. 2009, 15, 13308

(13) (a) Gulías, M.; García, R.; Delgado, A.; Castedo, L.; Mascareñas, J. L. J. Am. Chem. Soc. 2006, 128, 384. (b) Mascareñas, J. L.; García-Fandiño, R.; Gulías, M.; Castedo, L.; Granja, J. R.; Cardenas, D. J. Chem. Eur. J. 2008, 14, 272. (c) Durán, J.; Gulías, M.; Castedo, L.; Mascareñas, J. L. Org. Lett. 2005, 7, 5693. (d) Trillo, B.; Gulías, M.; López, F.; Castedo, L.; Mascareñas, J. L. Adv. Synth. Catal. 2006, 348, 2381. (e) López, F.; Delgado, A.; Rodríguez, J. R.; Castedo, L.; Mascareñas, J. L. J. Am. Chem. Soc. 2004, 126, 10262. (f) Mascareñas, J. L.; Delgado, A.; Rodríguez, J. R.; Castedo, L. J. Am. Chem. Soc. 
2003, 125, 9282. (g) Trillo, B.; Gulías, M.; López, F.; Castedo, L.; Mascareñas, J. L. J. Organomet. Chem. 2005, 690, 5609.

(14) For a Ni-catalyzed hydroalkynylation of styrenes, see: Shirakura, M.; Suginome, M. Org. Lett. 2009, 11, 523.

(15) The reaction could also be performed in other solvents but 5 aa was obtained in lower yields (toluene: $57 \%$ yield; $1,2-\mathrm{DCE}$ : $37 \%$ yield).

(16) The catalyst reported in ref. $14,\left(\mathrm{Ni}(\mathrm{COD})_{2} / \mathrm{PMePh}_{2}\right)$ also failed to give 5aa, majoritarily leading to enynes 6 .

(17) Preliminary tests indicated that $\alpha$-substituted enones were also unreactive under these conditions.

(18) There are very few precedents in the direct alkynylation of these types of Michael acceptors. See references 3c (enals), 4c (thioamides), and $6 \mathrm{a}$ and $8 \mathrm{a}$ (acrylates).

(19) Reetz, M. T.; Guo, H.; Ma, J.-A.; Goddard, R.; Mynott, R. J. J. Am. Chem. Soc. 2009, 131, 4136.

(20) Yields of these two examples are equivalent to those with phosphite L1, see table 2, entry 5, and table 3, entry 2.

(21) (a) Reaction of $\mathbf{1 b}-d$ with $\mathbf{4 e}$ :

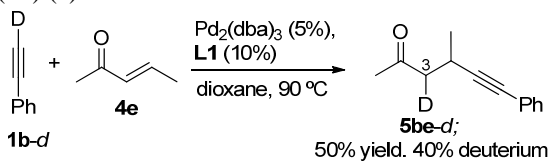

(22) ${ }^{2} \mathrm{H}$-NMR confirmed that deuterium was only incorporated at the internal alpha position of the ketone 5be-d.

(23) (a) All the calculations were carried using the Gaussian 03 rev. D.01 suite of programs. ZPE-corrected energies (B3LYP/6-31G(d) + LANL2DZ for Pd). Energy values $(\mathrm{kcal} / \mathrm{mol})$ are referred to $\mathbf{1 j}+\mathbf{P d}\left(\mathbf{P H}_{3}\right)+\mathbf{4 e}$. Gibbs energy is considered for drawing. For more computational details, see the Supporting Information. (b) We also performed DFT calculations with a Pd catalyst incorporating two $\mathrm{PH}_{3}$ ligands. However, after the initial C-H activation, the hydro-or carbopalladation must proceed with just one $\mathrm{PH}_{3}$ attached to the Pd like in the scheme 2. See the Supporting Information for further details.

(24) Reductive elimination from int-3, which lacks the carbonyl-Pd coordination, is $5.2 \mathrm{kcal}$ more costly than that from int-4.

(25) In qualitative agreement with the experimental results, the theoretical calculations also predict that a hydropalladation of enone $\mathbf{4 i}$, disubstituted at the $\beta$-position, is more difficult.

(26) Related hydrometallation pathways have only been previously suggested in a Rh- and a Ru-catalyzed process, see references 3a and 6d. 